\title{
Malignant Mystique: Porocarcinoma in Three Adult Filipinos
}

\author{
Juan Paolo David S. Villena, Blythe N. Ke and Cynthia P. Ciriaco-Tan \\ Department of Dermatology, College of Medicine and Philippine General Hospital, University of the Philippines Manila
}

\begin{abstract}
Porocarcinoma is a rare, cutaneous adnexal malignancy usually seen in elderly patients. We present three females with varying lesions located at the head region with a history of a sudden increase in growth. Histologically, all were composed of nests of basaloid cells showing atypia, mitotic figures and eccrine-differentiated ductal elements. One patient underwent excision $(0.5 \mathrm{~cm}$ margin) and was recurrence-free one-month post-op. This series also brings a brief review of the current literature on porocarcinoma.
\end{abstract}

Key Words: Porocarcinoma, eccrine porocarcinoma, malignant eccrine poroma

\section{INTRODUCTION}

Porocarcinoma is a rare cutaneous adnexal malignancy of the intraepidermal or acrosyringeal portion of the eccrine sweat gland. ${ }^{1,2,3}$ It is considered to be the most frequently encountered sweat gland tumor. It is more commonly seen in elderly patients ${ }^{4,5}$ with no known gender predilection. ${ }^{1}$ The most frequently involved sites are the lower extremities, followed by the head and neck region, the upper extremities and the trunk. ${ }^{6}$ There is no known clear pathophysiologic mechanism for its occurrence although several risk factors such as trauma, occupational radiation exposure, chronic sun exposure, exposure to different chemical agents and immunosuppression have been mentioned. ${ }^{4,5,7}$ There have been reports of lesions arising from pre-existing poromas ${ }^{6}$ but there are also de novo cases. ${ }^{2,8}$ Histopathologic examination is the gold standard for the diagnosis of porocarcinoma and is also used for prognostication. ${ }^{1}$ Currently, there are no standardized algorithms for the management of porocarcinoma. This may be attributed to the small number of affected individuals. ${ }^{1,3,9}$ In this case series, we present three cases of porocarcinoma, all arising from a relatively uncommon site, the head and neck region.

\section{CASE DESCRIPTIONS}

E-Poster presented at the $28^{\text {th }}$ European Academy of Dermatology and Venereology Congress, October 9-13, 2019, Madrid, Spain; and at the $42^{\text {nd }}$ Annual Convention of the Philippine Dermatological Society, November 5-7, 2019, Edsa Shangri-La, Mandaluyong City, Philippines.

Corresponding author: Juan Paolo David S. Villena, MD Department of Dermatology Philippine General Hospital

University of the Philippines Manila

Taft Avenue, Manila 1000, Philippines

Email: jpdsvillena@gmail.com

\section{Case 1}

MA, a 44-year-old female with no comorbidities, presented with an 18-year history of a right parietooccipital scalp tumor. It started as a solitary friable papule with occasional pain on palpation with minimal progression in size. Five years prior to consult, she noted an appearance of yellowish, malodorous discharge with no associated signs and symptoms. The patient sought consult at a local health center where she was given an unrecalled antibiotic ointment 

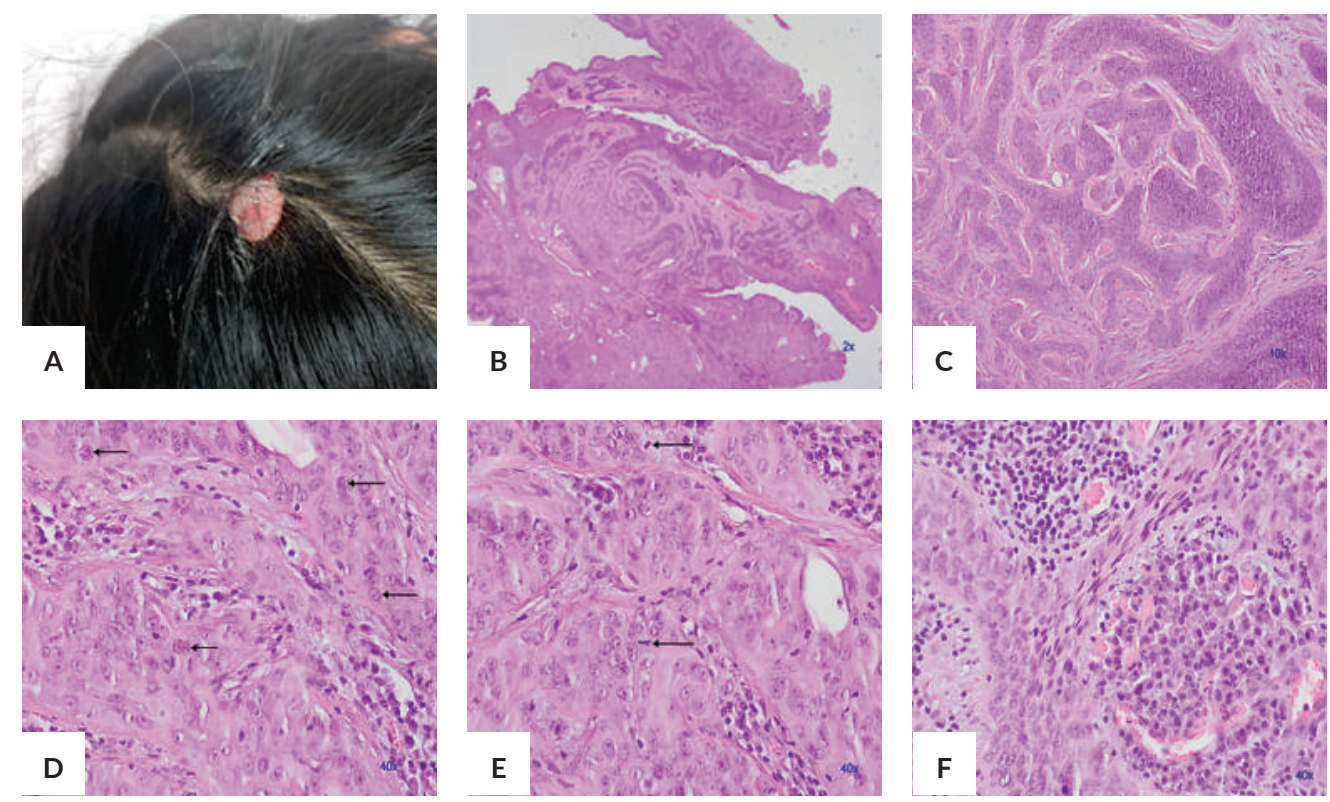

Figure 1. Scalp tumor of Case 1. Solitary, well-defined, pink oval tumor (A). 2x magnified view with hematoxylin \& eosin (H\&E) (B). 10x magnification with H\&E shows tumor nests (C). 40x magnification with H\&E reveals cellular atypia (black arrows, D), mitotic figures (black arrows, E) and lakes of lymphocytic and plasma cell (F).

and cloxacillin with a resolution of discharge. A year prior to consult, a sudden increase in size with no other signs and symptoms was noted. Two months prior to consult, the patient sought consult at a private hospital in Olongapo City, Philippines where a biopsy was done which showed basosquamous carcinoma. She was advised to get surgery, but the patient opted to have a second opinion done at this institution. Upon examination, a $1.5 \times 1.5 \times 0.6 \mathrm{~cm}$ solitary, well-defined, pink oval tumor on the parieto-occipital scalp with coarse scaling on the surface and a wide, non-tender base was observed (Figure 1A).

\section{Case 2}

CA, a 65-year-old female with no comorbidities, presented with a three-month history of a solitary, skincolored papule on the left malar area. She often scratched the area which led to erosion with minimal bleeding. Two weeks prior to consult, there was a sudden increase in the growth of the lesion. One week prior to consult, there was yellowish malodorous discharge with associated areas of focal ulceration prompting them to seek consult. Upon examination, a 2.7 x $1.8 \times 0.8 \mathrm{~cm}$ solitary pink firm well-defined nodule with prominent vessels and hemorrhagic crusting on the left malar area was observed (Figure 2A). On removal of the crust, focal ulceration was uncovered. Dermoscopy showed pink-white structureless areas, focal areas of ulceration, as well as arborizing telangiectasia.

\section{Case 3}

$\mathrm{CP}$, a 71-year-old female with no comorbidities, presented with a three-year history of a left malar nodule with occasional pruritus and minimal increase in size. Two months
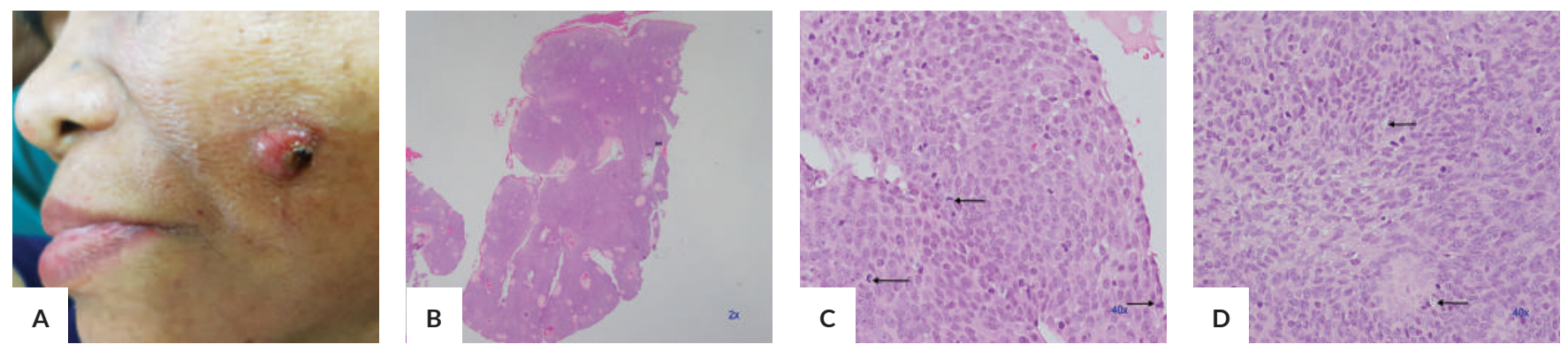

Figure 2. Left malar nodule of Case 2. Solitary pink firm well-defined left malar nodule (A). $2 x$ magnification (H\&E) shows tumor nests (B). 40x magnification (H\&E) shows mitotic figures (black arrows, C). 40x magnification (H\&E) shows ductal elements within the tumor nests (black arrows, D). 

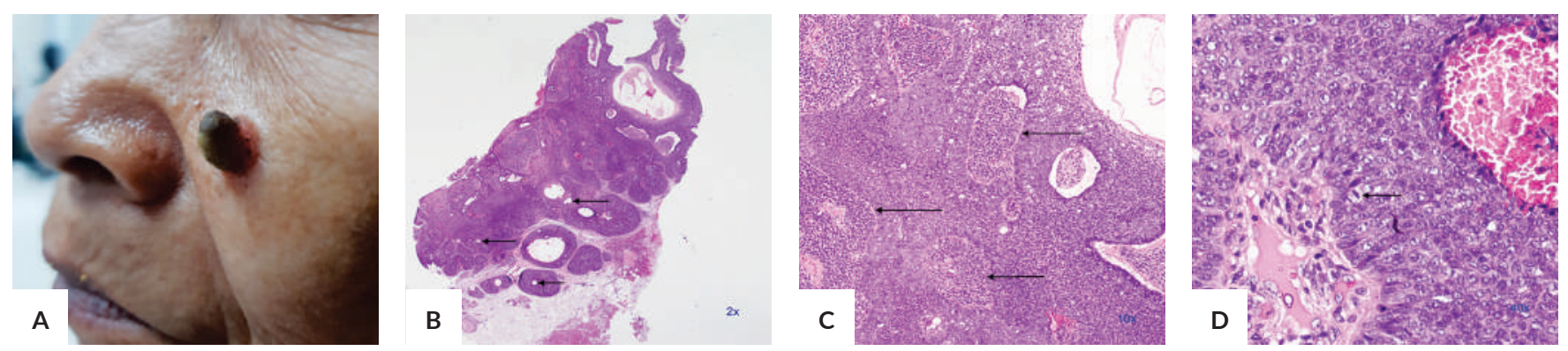

Figure 3. Left malar nodule of Case 3. Solitary tan-brown, verrucuous, left malar nodule (A). 2x magnification with H\&E shows ductal elements (black arrows, B). 10x magnification with H\&E shows lakes of lymphocytes and plasma cell (black arrows, C). 40x magnification with H\&E shows mitotic figures (black arrows, D).

prior to consult, she noted a sudden increase in size with the appearance of yellowish malodorous discharge overlying the nodule. No other signs and symptoms were noted. This prompted the patient to seek consult. On examination, a $0.9 \times 0.6 \times 0.7 \mathrm{~cm}$ solitary tan-brown, verrucous, tender nodule with an erythematous base over the left malar area was observed (Figure 3A). Dermoscopy showed focal areas of ulceration as well as arborizing telangiectasia which were most prominent at the base of the nodule.

\section{Histopathologic findings}

All three cases above had the same key features on histopathology. There were multiple nests of atypical basaloid cells (Figure 1B, Figure 1C, Figure 2B, Figure 3B) with nuclear pleomorphism (Figure 1D, Figure 2C, Figure 3D) and mitotic figures (Figure 1E, Figure 2C, Figure 3D) scattered in the tumor nests. All three lesions had ductal elements characteristic of eccrine differentiation, a pink cuticle without any form of decapitation secretion (Figure 1C, Figure 2D, Figure 3B). Lakes of inflammatory cell infiltrate composed of lymphocytes and plasma cells were also appreciated (Figure 1F, Figure 3C). There were no signs of lymphovascular invasion in all three cases. These findings are all consistent with porocarcinoma.

\section{DISCUSSION}

Porocarcinoma is a rare cutaneous adnexal malignancy of the acrosyringeal portion of the eccrine sweat gland and comprises $0.005-0.01 \%$ of all cutaneous neoplasms. ${ }^{3,6} \mathrm{It}$ is the most frequently encountered sweat gland tumor. It was first reported by Pinkus and Mehregan in 1963 where a glycogenrich cutaneous neoplasm was seen in an 82-year-old woman with multiple lymph node deposits and distant epidermotropic metastasis. ${ }^{4}$ It is mostly present in older patients. ${ }^{1,5}$ There is no known gender predilection ${ }^{1}$ but some reports show a slight female predominance. ${ }^{10}$ It generally favors the lowers extremities and is rarely found on the head and neck region as well as at the trunk and the upper extremities.

Porocarcinoma has a diverse clinical presentation. It often presents as a pink or flesh-colored nodule with nondescriptive morphology. The pathogenesis of porocarcinoma is still not well understood ${ }^{11}$ because of the small population of people affected by the disease. Most cases report a long duration of dormancy of a previous nodule with a sudden increase in its growth. ${ }^{5}$ The sudden increase in growth may be a malignant transformation from possible preexisting poroma, nevus sebaceous or actinic lesions. ${ }^{6}$ Somatic copy losses on several tumor suppressor genes have also been noted in a study on metastatic eccrine porocarcinoma which points to a possible genetic mechanism with a familial pattern but is still debatable. ${ }^{12}$ Trauma and occupational radiation exposure may have a role in tumor development but are still poorly understood. ${ }^{7}$ Chronic sun exposure, chemical exposure and immunosuppression may also be factors in the development of de novo porocarcinoma lesions.

Dermoscopy is also an invaluable tool for assessing cutaneous lesions where we have a high index of suspicion for malignancy. ${ }^{13}$ In this series, two out of the three lesions presented with arborizing telangiectasia, most commonly found in basal cell carcinoma as well as pink-white structureless areas, scaling and focal ulceration; however, according to a recent study by Mirakhor et al, dermoscopic features of porocarcinoma do not allow accurate differentiation against its counterparts. ${ }^{13}$ Current evidence favors histopathology as the gold standard for diagnosis. Histopathologic characteristics will also determine the prognosis of patients. ${ }^{4}$ Eccrine type of ductal structures, clear round areas lined by a pink cuticle is essential for diagnosis. ${ }^{4}$ They are characterized by nodular masses of basaloid cells, continuous with the overlying epidermis, infiltrating the dermis. ${ }^{11}$ There may be dyskeratotic keratinocytes found within the tumor fronds, focal areas of necrosis and lakes of lymphoplasmacytic infiltrate. ${ }^{11}$ Retraction artifacts, such as in basal cell carcinoma, may also be seen. Infiltrative borders may increase the possibility of distant metastasis. ${ }^{14}$ Immunostaining with pancytokeratin will show diffuse membrane positivity while carcinoembryonic antigen (CEA) and epithelial membrane antigen (EMA) will exhibit staining of the glandular elements and may aid in examining anaplastic variants. ${ }^{11,15}$ The constellation of clinical and histologic features are diagnostic for porocarcinoma. There is no association between 


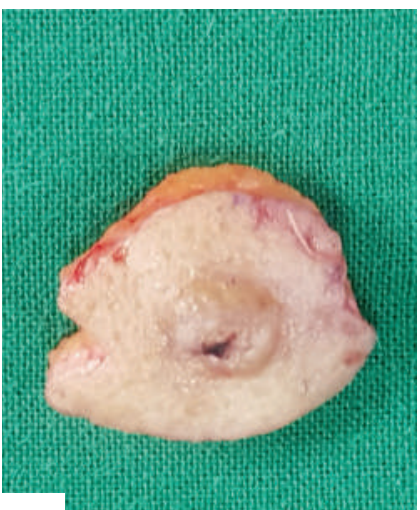

A
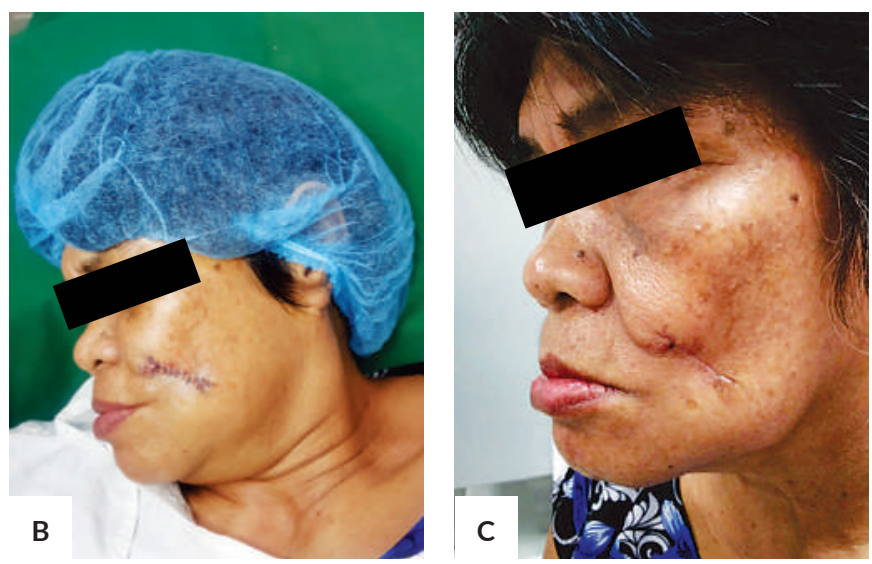

Figure 4. Excision of left malar nodule of Case 2. Left malar nodule measuring $2.4 \times 1.6 \times 1.8 \mathrm{~cm}$ (A). Closure of the defect via double M-plasty (B). Linear atrophic scar (C).
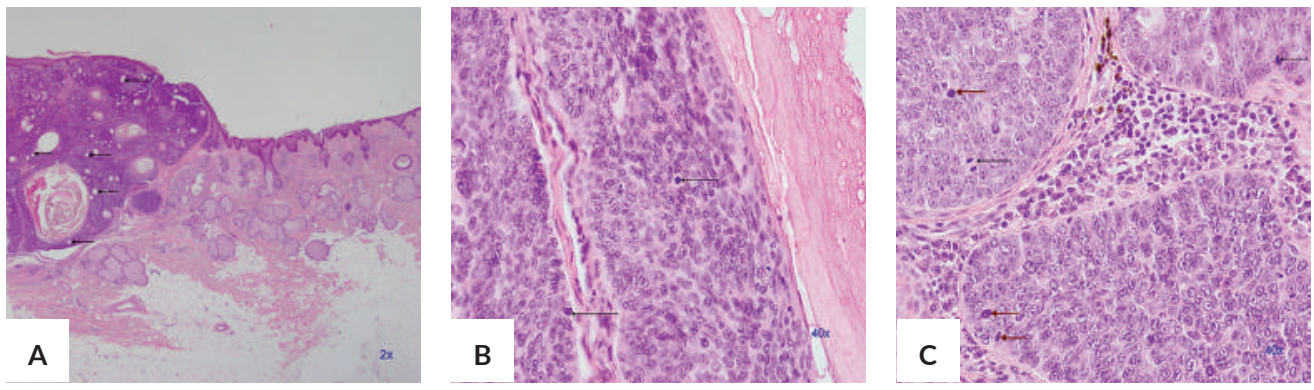

Figure 5. Histopathologic review of the excised nodule of Case 2. Tumor depth was $3.794 \mathrm{~mm}$ and surrounding margins were free from tumor. 2x magnification with H\&E shows ductal elements (black arrow) within the tumor nest (A). 40x with H\&E magnification shows some mitotic figures within the tumor (red and black arrows, B and C).

gross size of the tumor and prognosis; however, the following features point to a higher risk of developing nodal metastasis: tumor depth $>7 \mathrm{~mm},>14$ mitotic figures per high power field (/hpf) and lymphovascular invasion. ${ }^{4}$ Sentinel lymph node biopsy (SLNB) may be done to rule out nodal metastasis.

The recommended treatment is wide excision ${ }^{16}$ with 0.5-2.0 cm margins. ${ }^{3}$ Even with adequate margins, local recurrence is still seen in $20 \%$ of cases, regional and distant metastasis at $20 \%$ and $12 \%$, respectively. ${ }^{3}$ Other sites frequently involved are the lungs, liver, and brain. ${ }^{5}$ Mortality in patients with nodal metastasis may reach up to $65 \% .^{3}$ Multiple case series and reports currently suggest the use of Mohs micrographic surgery (MMS) in managing porocarcinoma. ${ }^{2,3,14,16}$ In a retrospective case series of 12 eccrine porocarcinomas, only one patient developed lymph node metastasis, two years after MMS. ${ }^{3}$ In one case report, a 79-year-old female with porocarcinoma of the left leg was treated using external beam radiation therapy. ${ }^{17}$ They noted local and remote control of the disease at 5 and 24-month intervals with grade 1 radiation dermatitis being the only observed adverse event. ${ }^{17}$ Excellent results were noted in a case of metastatic porocarcinoma treated using a combination of surgery, oral isotretinoin and radiotherapy. ${ }^{18}$
MA was referred to another institution for MMS. CP was lost to follow-up. Patient CA had wide excision done with a $0.5 \mathrm{~cm}$ margin around the nodule. (Figure $4 \mathrm{~A}$, Figure $4 \mathrm{~B}$, Figure 4C). The lesion measured $2.4 \times 1.6 \times 0.8 \mathrm{~cm}$ (Figure 4A). Tumor margins were clear (Figure 5A). The deepest tumor was found to be at $3.794 \mathrm{~mm}$ from the granular cell layer. Mitotic figures seen were 1-2/hpf (Figure 5B, Figure 5C). There was no note of lymphovascular invasion and borders were not infiltrating. One month after excision, there were no palpable lymph nodes and no recurrence of the disease.

\section{CONCLUSION}

In summary, three morphologically varied lesions sharing key characteristics of histopathology were presented. All lesions were composed of nests of atypical basaloid cells with mitotic figures as well as eccrine-differentiated ductal elements, which are all consistent with the diagnosis of porocarcinoma. Because of its morphologic variety as well as nonspecific evolution, a biopsy is still the gold standard of diagnosis especially in lesions where there is a high index of suspicion of any kind of malignancy. Dermoscopic findings in porocarcinoma lesions are non-specific. As of 
the moment, wide surgical excision with adequate margins is still the primary treatment modality for porocarcinoma. By performing excision with adequate margins, tumor characteristics that will determine the patient's prognosis may be assessed. Emerging studies, however, are pointing towards the use of MMS in the treatment of porocarcinoma.

\section{Statement of Authorship}

All authors participated in data collection and analysis, and approved the final version submitted.

\section{Author Disclosure}

All authors declared no conflicts of interest.

\section{Funding Source}

This paper was funded by the authors.

\section{REFERENCES}

1. Gómez-Zubiaur A, Medina-Montalvo S, Vélez-Velázquez MD, Polo-Rodríguez I. Eccrine porocarcinoma: patient characteristics, clinical and histopathologic features, and treatment in 7 cases. Actas Dermosifiliogr. 2017; 108(4):e27-32.

2. Luz Mde A, Ogata DC, Montenegro MF, Biasi LJ, Ribeiro LC. Eccrine porocarcinoma (Malignant eccrine poroma): a series of eight challenging cases. Clinics. 2010; 65(7):739-42.

3. Xu YG, Aylward J, Longley BJ, Hinshaw MA, Snow SN. Eccrine porocarcinoma treated by Mohs micrographic surgery: over 6-year follow-up of 12 cases and literature review. Dermatol Surg. 2015; 41(6):685-92.

4. Robson A, Path MRC, Greene J, Kim B, Calonje E. Eccrine Porocarcinoma (Malignant Eccrine Poroma). Am J Surg Pathol. 2001; 25(6):11.

5. Salih AM, Kakamad FH, Baba HO, Salih RQ, Hawbash MR, Mohammed SH, et al. Porocarcinoma; presentation and management, a meta-analysis of 453 cases. Ann Med Surg. 2017; 20:74-9.
6. Rana RE, Verma SS, Puri VA, Baliarsing AS. Sweat gland tumor (Eccrine Porocarcinoma) of scalp: A rare tumor. Indian J Plastic Surg. 2005; 38(1):51-3.

7. Rafiei R, Eftekhari H, Daryakar A, Nickhah N, Rafiee B. Eccrine porocarcinoma: a case report and brief review of the literature. Our Dermatol Online. 2016; 7(4):391-3.

8. Asghar AH, Mahmood H, Faheem M, Rizvi S, Khan KA, Irfan J. Porocarcinoma: A Rare Sweat Gland Malignancy. J Coll Physicians Surg Pak. 2009; 19(6):389-90.

9. Kurashige Y, Minemura T, Nagatani T. Eccrine Porocarcinoma: clinical and pathological report of eight cases. Case Rep Dermatol. 2013;5(3):259-66.

10. Riera-Leal L, Guevara-Gutiérrez E, Barrientos-García JG, Madrigal-Kasem R, Briseño-Rodríguez G, Tlacuilo-Parra A. Eccrine porocarcinoma: epidemiologic and histopathologic characteristics. Int J Dermatol. 2015; 54(5):580-6.

11. Calonje E, Brenn T, Lazar A. Tumors of the sweat glands. In: McKee's Pathology of the Skin with Clinical Correlations, 4th ed, Vol. 2. China: Elsevier Saunders; 2012. pp. 1535-1538.

12. Thibodeau ML, Bonakdar M, Zhao E, Mungall KL, Reisle C, Zhang W, et al. Whole genome and whole transcriptome genomic profiling of a metastatic eccrine porocarcinoma. NPJ Precis Oncol. 2018; 2(1):8.

13. Mirakhor E, Nazareth MR, Bogner PN. Letters and Communications. In: American Society for Dermatologic Surgery. 2017; 2.

14. Bernet LL, Rieger KE, Swetter SM, Egbert BM, Lai JC. Outcomes of surgically-resected eccrine porocarcinoma with low-risk histologic features. J Dermatolog Clin Res. 2016; 4:1066.

15. Masamatti SS, Narasimha A, Bhat A, Chowdappa V. Eccrine porocarcinoma of the scalp: a rare case report with review of literature. J Clin Diagn Res. 2016; 10(1):ED15-ED16.

16. Nazemi A, Higgins S, Swift R, In G, Miller K, Wysong A. Eccrine porocarcinoma: new insights and a systematic review of the literature. Dermatol Surg. 2018; 44(10):1247-61.

17. Esqueda-Guerrero PD, Bautista-Hernández MY. Radiotherapy in eccrine porocarcinoma: literature review. Gaceta Mexicana de Oncologia. 2017; 16(5):284-88.

18. Melgandi W, Benson R, Hakin A, Bhasker S. Porocarcinoma scalp with high risk features treated with surgery and adjuvant radiotherapy: A case report and review of literature. J Egypt Natl Canc Inst. 2016; 28(3):195-8. 